www.jkns.or.kr

\section{Case Report}

II Sup KIM, M.D.

Sang Won Lee, M.D., Ph.D.

Byung Chul Son, M.D., Ph.D.

Jae Hoon Sung, M.D., Ph.D.

Department of Neurosurgery

St. Vincent's Hospital

The Catholic University of Korea

Suwon, Korea
- Received : February 25, 2008

- Accepted : May 7, 2008

- Address for reprints :

Sang Won Lee, M.D., Ph.D.

Department of Neurosurgery

St. Vincent's Hospital, The Catholic

University of Korea, 93-6 Ji-dong

Paldal-gu, Suwon 442-723, Korea

Tel : +82-31-249-7190

Fax : +82-31-245-5208

E-mail : nslsw@yahoo.com

\title{
Posterior Epidural Migration of Thoracic Disc Fragment
}

\begin{abstract}
Migration of a disc fragment to the posterior epidural space is rare, especially in the thoracic spine. Only four such cases of posterior epidural migration of thoracic disc fragments have been reported. The authors report a case of 66-year-old man who presented with back pain and right leg weakness due to posterior epidural migration of thoracic disc fragment. The patient was successfully treated by laminectomy and partial facetectomy with disc removal.
\end{abstract}

KEY WORDS : Thoracic disc herniation • Migration • Posterior epidural space • Magnetic resonance imaging.

\section{INTRODUCTION}

Only $0.15 \%$ to $4 \%$ of all symptomatic herniations of a disc are in the thoracic spine ${ }^{1)}$. Herniated disc fragments are known to migrate within the spinal canal in rostral, caudal, and lateral directions ${ }^{6,14,22)}$. Posterior epidural migration of herniated disc fragments are rare and most cases have been reported in lumbar region ${ }^{2,4,5,8,12,17,19,20)}$. These posterior epidural migration in thoracic region are even more infrequent, with only four cases previously reported ${ }^{3,16-18)}$. We report a case of a 66-year-old man who presented with back pain and right leg weakness due to the posterior epidural migration of thoracic disc fragment.

\section{CASE REPORT}

\section{History and examination}

This 66-year-old man presented with a 3 days history of back pain and right leg weakness. There was no history of trauma. Three years ago, he suffered from spontaneously developed back pain and was treated with intermittent physical therapy. On admission, he could not walk by himself due to right leg weakness.

A physical examination did not reveal any notable findings except back pain and right leg weakness. The straight leg raising test and deep tendon reflex test were within normal limits. The motor powers of right leg hip flexion, foot dorsi-flexion, and foot plantar flexion were checked to grade $3 / 5$, but those of left leg were normal. Sensory, bladder, and bowel functions were normal.

A magnetic resonance imaging (MRI) revealed a marked spinal stenosis at T10-11 level with a posterior epidural mass, about $1.2 \times 0.8 \mathrm{~cm}$ in size. The mass showed decreased signal on T1-weighted images (T1WI), increased signal on T2-weighted images (T2WI), and rim-enhancement, and combined right subarticular disc extrusion at T10-11 with thecal sac indentaion (Fig. 1).

\section{Operation}

Total laminectomy of T10 was performed under somato-sensory evoked potential monitoring. After removal of thickened ligament flavum, dorsal and lateral compressing fibrous epidural mass which was tightly adherent to thecal sac, was noticed (Fig. 2). The mass extended into epidural space laterally, so additional partial medial facetectomy was performed. Dorsal epidural fibrous mass and lateral soft mass were removed carefully. During operation, there was no conduction delay in somato-sensory evoked potential. 

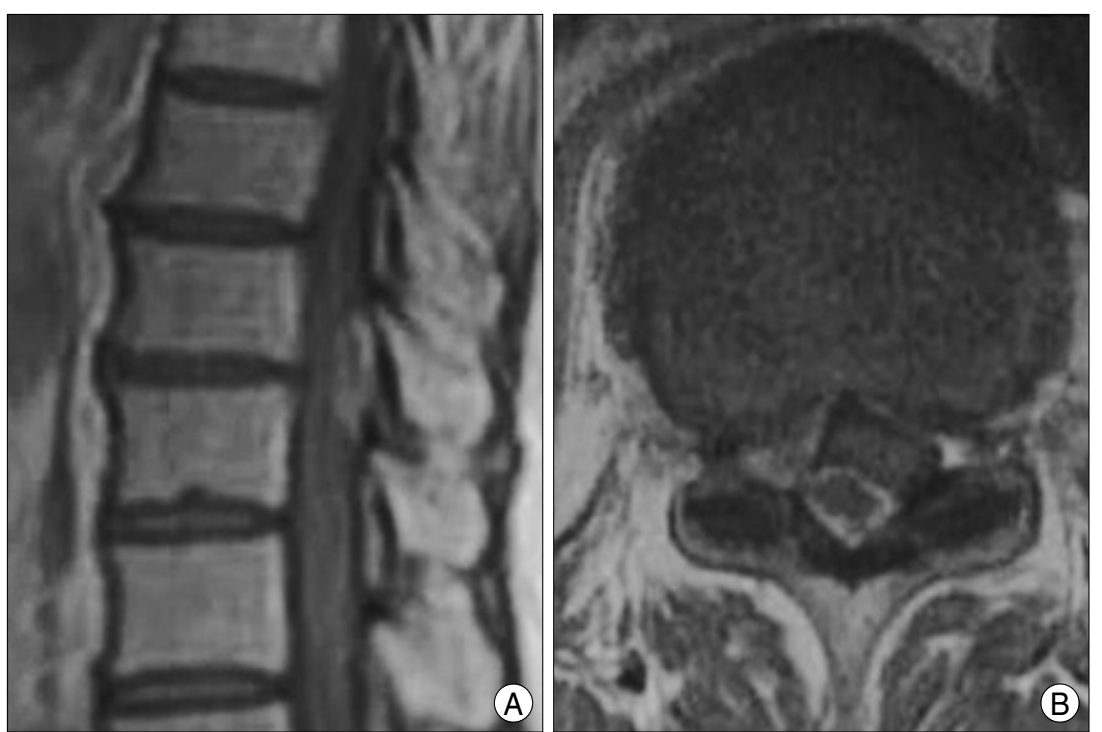

Fig. 1. A : Left Sagittal gadolinium-enhanced T1-weighted magnetic resonance image (MRI) of thoracic spine revealing a mass lesion with increased signal at the posterior extradural space at the T10-11 level. B : Axial gadolinium-enhanced T1-weighted MRI at T10-11 disc level showing a rim enhancement of the posterior extradural disc material, compressing the dura, and combined right subarticular disc extrusion with thecal sac indentation.

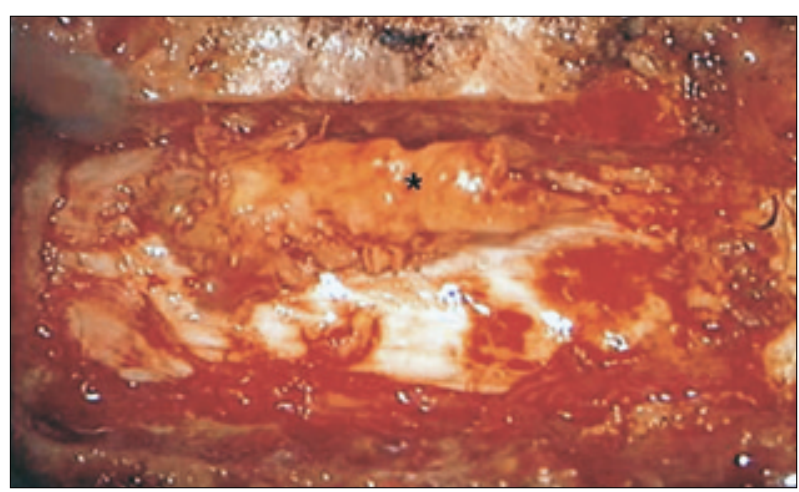

Fig. 2. Intraoperative photograph showing the posterior extradural migrated disc fragment (asterisk), which is tightly adherent to thecal sac and communicated with lateral soft disc.

\section{Postoperative course}

The histologic examination revealed degenerated fibrocartilagenous tissue and calcification, consistent with herniated disc. His weakness improved postoperative immediately, and could walk with mild weakness of right leg.

\section{DISCUSSION}

Several mechanisms of posterior migration of the disc material have been proposed ${ }^{9,11}$. Slight adhesion between the annulus fibrosus and the dural sac caused by previous asymptomatic disc herniation may accelerate the posterior migration of the sequestrated disc material. Acute strong pressure may then push the disc material to the posterior site of the dural sac. If the laceration of the annulus fibrosus occurs in the lateral point near the pedicle, the sequestrated disc material may migrate along the medial site of the pedicle to the lateral and posterior sides of the dural sac.

Because of the anatomy of the anterior epidural space (AES), most of the sequestrated disc fragment usually migrate in lateral direction in the spinal canal ${ }^{6,22)}$. Schelling et al. concluded that the migrating path of a disc fragment is determined by the anatomy of the AES, a fairly welldefined space delimited posteriorly by the posterior longitudinal ligament (PLL) and lateral membrane, attached medially to the free edge of the PLL, and stretches laterally to the wall of the spinal canal ${ }^{21)}$. Not only these PLL and lateral membrane, but also epidural vessels, fat and nerve roots limit posterior epidural migration of herniated disc fragments ${ }^{6,13,22)}$.

MRI, especially with gadolinium administration, appears to be the method of choice for diagnosis. Sequestrated fragments usually show low signal intensity on T1WI, and $80 \%$ of cases exhibit high signal intensity on T2WI relative to the degenerated disc of origin ${ }^{15}$. The high signal intensity on T2WI can be explained as either the herniated material still having a higher water content than an intact disc or a reparative process leading to a transient water gain ${ }^{15)}$. Most of the disc fragments show peripheral contrast enhancement attributed to an inflammatory response with granulation tissue and newly formed vessels around the sequestrated tissue as shown in the present report $^{10)}$. In our patient, there was communication between posterior epidural mass and the lateral protruded disc material. In most of the reported cases, preoperative diagnosis was difficult and confused with other posterior epidural space occupying lesions, such as hematoma, synovial cyst, epidural abscess, metastatic tumor, and meningioma ${ }^{2-5,8,12,16-20)}$.

Hematoma usually has isointensity or hypointensity on T1WI, no enhancement, and an associated trauma history, but hematoma in resolving state can also appear as a rimenhancing lesion ${ }^{7}$. Synovial joint cyst shows similar to cerebrospinal fluid in image intensity, and related to facet joint, but does not show enhancement. Epidural abscess shows iso- to hypointensity compared with the spinal cord 
on T1WI, and increased intensity on proton-density- and T2WI, and rim-enhancement ${ }^{21)}$. Epidural abscess also shows a combination of a frank abscess and tissue enhancement. Metastatic tumor usually has destructive adjacent bony changes, and different patterns of homogeneous or heterogeneous enhancement ${ }^{23}$. Meningioma shows isointense to slightly hyperintense signal on T2WI and homogeneous enhancement. Most of meningiomas locate at intradural space, rarely locate at both intra- and extradural or extradural space.

There have been reported several cases of posterior epidural migration of herniated disc fragments in lumbar area, but only four cases have been reported in thoracic area in the literature $\mathrm{r}^{2-5,8,12,16-20)}$.

\section{CONCLUSION}

We have described the rare case of back pain and right leg weakness in a patient with posterior epidural migrated disc herniation in thoracic region. Although it is difficult to make exact diagnosis of posterior epidural migration of thoracic disc herniation by MRI alone, especially in case of the communication between rim-enhancing epidural mass and disc space, one must consider the possibility of posterior epidural migrated disc fragment.

\section{References}

1. Awwad EE, Martin DS, Smith KR Jr, Baker BK : Asymptomatic versus symptomatic herniated thoracic discs : their frequency and characteristics as detected by computed tomography after myelography. Neurosurgery $28: 180-186,1991$

2. Bonaroti EA, Welch WC : Posterior epidural migration of an extruded lumbar disc fragment causing cauda equina syndrome. Clinical and magnetic resonance imaging evaluation. Spine 23 : 378-381, 1998

3. Bose B : Thoracic extruded disc mimicking spinal cord tumor. Spine J $3:$ : 82-86, 2003

4. Choi BJ, Kim DH, Park HS, Rhee DY : Posterior migration of extruded lumbar disc fragments-case report. J Korean Neurosurg Soc $41: 137-140,2007$

5. Dosoglu M, Is M, Gezen F, Ziyal MI : Posterior epidural migration of a lumbar disc fragment causing cauda equina syndrome : case report and review of the relevant literature. Eur Spine J $10: 348-351$, 2001

6. Ebeling U, Reulen $\mathrm{HJ}$ : Are there typical localisations of lumbar disc herniations? A prospective study. Acta Neurochir (Wien) 117 : 143-148, 1992

7. Eerens I, Demaerel P, Haven F, van Loon J, Van Calenbergh F, Wilms $G$ : Imaging characteristics of noncontained migrating disc fragment and cyst. Eur Radiol 11 : 854-857, 2001

8. Eysel P, Herbsthofer B : Dorsal compression of the epidural cord due to free sequestral lumbar prolaps. Diagnostic problems in magnetic resonance imaging and computed tomography. Arch Orthop Trauma Surg $121: 238-240,2001$

9. Fisher RG : Protrusions of thoracic disc. The factor of herniation through the dura mater. J Neurosurg 22:591-593, 1965

10. Hwang GJ, Suh JS, Na JB, Lee HM, Kim NH : Contrast enhancement pattern and frequency of previously unoperated lumbar discs on MRI. J Magn Reson Imaging $7: 575-578,1997$

11. Isla A, Roda JM, Bencosme J, Alvarez MP, Blazquez MG : Intradural herniated dorsal disc : case report and review of the literature. Neurosurgery $22: 737-739,1988$

12. Lichtor $\mathrm{T}$ : Posterior epidural migration of extruded lumbar disk. Surg Neurol $32: 311-312,1989$

13. Loughenbury PR, Wadhwani S, Soames RW : The posterior longitudinal ligament and peridural (epidural) membrane. Clin Anat $19: 487-492,2006$

14. Manabe S, Tateishi A : Epidural migration of extruded cervical disc and its surgical treatment. Spine $11: 873-878,1986$

15. Masaryk TJ, Ross JS, Modic MT, Boumphrey F, Bohlman H, Wilber G : High-resolution MR imaging of sequestered lumbar intervertebral disks. AJR Am J Roentgenol 150 : 1155-1162, 1988

16. Morizane A, Hanakita J, Suwa H, Ohshita N, Gotoh K, Matsuoka $\mathrm{T}$ : Dorsally sequestrated thoracic disc herniation-case report. Neurol Med Chir $11: 769-772,1999$

17. Neugroschl C, Kehrli P, Gigaud M, Ragragui O, Maitrot D, Manelfe C, et al : Posterior extradural migration of extruded thoracic and lumbar disc fragments : role of MRI. Neuroradiology 41 : 630635, 1999

18. Partheni M, Fratzoglou M, Kalogeropoulou Ch, Zabakis P, Panagiotopoulos V, Konstantinou D : Dorsal extradural thoracic disc fragment : a diagnostic challenge. J Spinal Disord Tech 18 : 544546,2005

19. Robe P, Martin D, Lenelle J, Stevenaert A : Posterior epidural migration of sequestrated lumbar disc fragments. Report of two cases. J Neurosurg 90 (2 Suppl) : 264-266, 1999

20. Sakas DE, Farrell MA, Young S, Toland J : Posterior thecal lumbar disc herniation mimicking synovial cyst. Neuroradiology 37 : 192194, 1995

21. Sandhu FS, Dillon WP: Spinal epidural abscess : evaluation with contrast-enhanced MR imaging. AJNR Am J Neuroradiol 12 : 1087-1093, 1991

22. Schellinger D, Manz HJ, Vidic B, Patronas NJ, Deveikis JP, Muraki AS, et al : Disk fragment migration. Radiology $175: 831-836,1990$

23. Sze G : Magnetic resonance imaging in the evaluation of spinal tumors. Cancer 67 (4 Suppl) : 1229-1241, 1991 